Marina Becerra

Universidad de Buenos Aires

\title{
'¿Qué quieren las mujeres?' Ciudadanía femenina y escrituras de la intimidad en la Argentina de inicios del siglo $X X$
}

\begin{abstract}
Resumen: Las llamadas 'escrituras de la intimidad' - autobiografías, cartas, relatos de viajes, diarios íntimos - permiten analizar los deslizamientos posibles entre lo público y lo privado en una coyuntura histórica en la cual los derechos para cada sexo estaban claramente predefinidos en cada uno de los espacios de acción. Es decir que, desnaturalizando el presente al narrarlo, las 'escrituras de la intimidad' permiten pensar las estrategias de las mujeres, confinadas por ley al espacio doméstico, de proyectar sus voces en la esfera pública. A partir del irresoluble enigma planteado por una de las primeras voces masculinas que defendieron los derechos de las mujeres en Argentina - el socialista Enrique Del Valle Iberlucea -, aquí analizo cómo es contada - ¿vivida, representada? - la ciudadanía por las propias mujeres. Para ello, analizo los relatos de viajes de la escritora y maestra normal Ada María Elflein (1880-1919).
\end{abstract}

Palabras clave: ciudadanía femenina; escrituras de la intimidad; socialismo; relatos de viajes.

Copyright (๑) 2012 by Revista Estudos Feministas.

' Enrique Del Valle Iberlucea (1877-

1921) fue senador nacional por el socialismo desde 1913 a 1921. Ese año, la mayoría conservadora del Senado le inició un proceso de desafuero por su apoyo incondicional a la Revolución Rusa y a la Tercera Internacional, o, en términos muy sintéticos, por su 'traición de clase' (Marina BECERRA, 2009, p. 161). Apenas conocido como 'el primer senador socialista de América', fue sin embargo una de las primeras voces masculinas que, en la Argentina, reclamaron derechos civiles para las mujeres. En

\section{Introducción}

En 1902, el intelectual socialista español/argentino Enrique Del Valle Iberlucea ${ }^{\prime}$ dictaba una conferencia sobre el divorcio en el Centro Socialista Femenino de Buenos Aires. Allí se preguntaba, desilusionado, cómo era posible que 'Ias damas argentinas' hubieran ido en procesión al congreso para pedir el rechazo del primer proyecto de ley de divorcio vincular que se trataba en la Cámara de Diputados. ${ }^{2}$ El proyecto había sido presentado en 1901 por el diputado liberal Carlos Olivera y había movilizado fuertes corrientes de opiniones en torno del tema.

¿Cómo explicar entonces esta 'contradicción'? interrogaba el socialista Del Valle, ¿cómo es posible que las propias mujeres rechazaran el proyecto de divorcio?, ¿qué 
adelante aparece en el texto como Del Valle y en las citas como DVI.

${ }^{2}$ El diputado liberal Juan Balestra había presentado el primer proyecto de divorcio vincular en 1888 , pero ni siquiera fue tratado por la comisión correspondiente por lo que jamás llegó al recinto. Tanto Balestra como Olivera perte necían al Club Liberal, institución desde la cual se promovían las ideas de establecer el matrimonio civil, el registro civil, la supresión de los tribunales eclesiásticos para los asuntos de familia, y la educación laica y común.

${ }^{3}$ Esta pregunta remite a Sigmund Freud (1856-1939), contemporáneo de Del Valle.

${ }^{4}$ DVI, 1919, p. 206.

${ }^{5}$ DVI, 1919, p. 207.

${ }^{\circ}$ Dora BARRANCOS, 2007, p. 90

en

pasa con las mujeres como sujeto político?, ¿qué pasa con su libertad y la ciudadanía?, ¿qué quieren las mujeres?:3 "me causa profundo dolor que sean ellas mismas quienes piden a voces, clamando al cielo, como el esclavo de la tradición, que se remachen sus cadenas y se las mantenga en la servidumbre"4.

Del Valle arriesga una hipótesis: plantea que esta resistencia es el producto de la deficiente instrucción de las mujeres. Alienadas desde hace varios siglos en una cultura patriarcal, temen la ley de divorcio porque las expondría a ser abandonadas por sus maridos. Así, en una inversión paternalista, adjudica a los hombres la responsabilidad de esta falta de educación de las mujeres. En este punto coincidían los anarquistas, quienes también consideraban que era deber del hombre educar y guiar a la mujer. De todos modos, Del Valle, marxista heterodoxo, finaliza la conferencia acentuando la presencia femenina de su público, también 'damas argentinas' que, a diferencia de aquellas que asumen su opresión como un hecho natural, anhelan la emancipación legal: "[...] queréis romper vuestras cadenas [...] iréis a las puertas del congreso a pedir a nuestros legisladores que conviertan en ley el proyecto de divorcio, haciendo así obra de justicia, de civilización y de libertad". ${ }^{5}$

La tarea pedagógica que se autoasignaba el partido socialista, no sólo con los niños, sino también con otros sujetos sometidos, negados o temidos - como el gaucho y la mujer -, se evidencia en esta posición paternalista desde la cual Del Valle marca la diferencia entre las mujeres que asumen su lugar en la historia como un hecho natural y aquellas que luchan por sus derechos, es decir, por cambiar su propia historia.

En la Argentina de la temprana modernización liberal, las mujeres estaban reducidas a la esfera doméstica, y la exclusión sobre la que se sostenía la hegemonía patriarcal implicaba nuevos movimientos compensatorios hacia las mujeres. Estos movimientos eran visibles, entre otras formas, en la celebración de la figura de la madre. ${ }^{6}$ En efecto, los primeros discursos que interpelaron a las mujeres desde el Estado lo hicieron en tanto 'madres', sin nombrarlas como individuos o ciudadanas. Sin embargo, también existían discursos que planteaban formas alternativas de relaciones entre los sexos, que intuían que la producción de ciudadanía es atravesada en primer plano por la dimensión de género. A partir del análisis histórico de las relaciones entre los sexos, Del Valle - junto a las feministas socialistas y a algunos hombres de su mismo partido - luchaba por desnaturalizar los roles sexuales, es decir, intentaba desarmar la violencia simbólica que organizaba las posiciones masculinas y femeninas en la sociedad. Del Valle 
utiliza con frecuencia este procedimiento: la función de la ciencia histórica sería la de desnaturalizar lo dado, lo que aparece socialmente como evidente porque fue naturalizado dentro de los valores hegemónicos, 'patriarcales', para utilizar los términos textuales de Del Valle. En este sentido, para Del Valle la historia asume un valor fuertemente crítico para subvertir los valores naturalizados en el sentido común, como la extendida idea sobre la 'inferioridad natural' de las mujeres. Esta 'inferioridad natural' femenina formaba parte del discurso tradicional de los sectores más conservadores, vinculados al clero, pero también se justificaba con argumentos pretendidamente científicos, vinculados al evolucionismo dominante en las primeras décadas del siglo. $Y$ estos cuestionamientos, provenientes de voces como las de Del Valle y las socialistas feministas, han habilitado otra concepción de ciudadanía, fundada en la tensión entre universal y particular. Esta concepción universalista de ciudadanía alojaba conflictivamente una visión particularista, basada en el género. Pero no es posible reducir esta tensión a ninguno de los dos ejes que sostienen los estereotipos tradicionales de los géneros: ni a la idea de ciudadano abstracto y racional, ni a la división por género de las esferas pública y privada. Por el contrario, esta tensión se sostiene en una concepción de las relaciones entre lo femenino y lo masculino, entre vida pública y vida privada, menos jerárquica, basada en la idea de equivalencia.

A partir de la desconcertada pregunta de Del Valle, en este trabajo me propongo entonces analizar, en la propia voz de las mujeres, cómo era vivida la ciudadanía por ellas mismas. Para ello, he tomado como objeto de análisis las escrituras de la intimidad femenina en la época bajo estudio. En esta ocasión, por motivos de espacio, me he centrado en una de aquellas mujeres, poco explorada hasta el momento: la escritora y maestra normal Ada María Elflein (1880-1919).

\section{Voces femeninas}

¿Cómo se producen - y reproducen - los estereotipos de género en determinada época histórica?, ¿cómo se configura lo femenino y lo masculino hegemónico, aquello que se espera de 'la' mujer y de 'el' varón, y de sus relaciones?, ¿en qué órdenes era posible para las mujeres plantear discontinuidades o rupturas con dichos mandatos sociales?, ¿cómo influía la adscripción de clase en los diversos posicionamientos de las mujeres escritoras - tanto en la reproducción acrítica de los mandatos, así como en los cuestionamientos de diversas dimensiones de lo social?

En los tiempos del Centenario, bajo los signos de la modernización liberal, la producción de las relaciones entre 
Io masculino y lo femenino se ha vinculado con la construcción de las esferas de lo público y lo privado asociadas al ejercicio de determinados derechos en función del sexo. Los discursos maternalistas jurídicos y políticos hegemónicos - que estructuraban la vida cotidiana ubicaban a las mujeres como inferiores a los hombres, y éstas eran definidas por la carencia, frente al modelo masculino naturalizado. Así, quedaban reducidas exclusivamente al espacio doméstico.

En este contexto opresivo emergían diversas posiciones y acomodaciones en las luchas por la inclusión, frente al discurso patriarcal que excluye a las mujeres de la vida pública. Estas posiciones van desde la oposición frontal y explícita, pasando por diferentes grados de asimilación con mayores o menores resistencias, hasta una aceptación pasiva de los términos patriarcales. La adscripción de género, cruzada con las de clase y nacionalidad, incide de diversos modos en los posicionamientos frente al discurso hegemónico que circunscribe el rol de las mujeres a la casa y la reproducción.

En este sentido, impulsadas quizás por la apertura de espacios culturales antes reservados a los varones, algunas mujeres publicaban sus escritos, desafiando en ese gesto, o al menos relativizando, las convenciones patriarcales de la época. Es decir que, en algunos casos, cuestionaban de diversas formas - directas o indirectas los estereotipos femeninos y masculinos definidos en la producción de una ciudadanía exclusiva para los varones, como fue la sanción y la implementación de la Ley Sáenz Peña conocida como 'ley de sufragio universal', del año 1912. En el esquema de organización social patriarcal afirmado en las leyes del siglo XIX, la defensa de los sentimientos en la esfera pública, puesta en escena por algunas mujeres en sus escritos, da cuenta de un cierto deslizamiento frente a la concepción liberal de la división de las esferas pública y privada - división que expresa, en tanto la reproduce, la distinción jerárquica entre los sexos. Si la esfera pública constituye el espacio de la abstracción, la imparcialidad y la razón, propia de los hombres, la esfera privada representaría el orden de lo privado, de las determinaciones, de lo concreto y de las sensaciones, atribuciones adjudicadas a las mujeres. Inscriptas en una construcción ideológica que propone un orden esquemático y binario de identidades estables, se podría pensar que las hoy llamadas 'escrituras de la intimidad' - encauzadas en variados géneros discursivos y literarios como las autobiografías, las cartas, los relatos de viajes, el diario íntimo - constituyen puentes entre un orden privado, íntimo, y otro orden, público, en el cual los sentimientos de las mujeres 
podrían circular bajo la forma de escritos publicados, en muchos casos, años después de la instancia de la escritura. En este sentido, el híbrido género 'escrituras de la intimidad' constituye un acceso privilegiado para analizar los deslizamientos posibles entre lo público y lo privado en una coyuntura histórica en la cual los derechos para cada sexo estaban claramente predefinidos en cada uno de los espacios de acción.

Asimismo, desnaturalizando el presente al narrarlo, aquellas autobiografías, diarios de viajes, etc., permiten también pensar las estrategias posibles de las mujeres, confinadas por ley al espacio doméstico, de proyectar sus voces en el espacio público. Pues el acceso de las mujeres al espacio público estaba reservado en el mejor de los casos a sus actividades en el magisterio - una continuación por otros medios de sus funciones maternales - o como mano de obra barata sin calificación, junto a los niños. Otra actividad aceptada socialmente era el trabajo de la poetisa: si contaban con alguna formación, las mujeres podían dedicarse a escribir poesías, pero siempre en tono sentimental.

En este sentido, las autobiografías, diarios y/o cartas de María Rosa Oliver, Delfina Bunge, Julia Valentina Bunge, Anaís Vialá, Victoria Ocampo, Norah Lange, y los diarios de viaje de la escritora y maestra Ada María Elflein, entre otras, nos ofrecen imágenes múltiples. Por un lado, son voces de mujeres que se proyectan en el espacio público, reservado a los varones, pero con un sesgo identificado en esos años como específicamente femenino, que es el relato de la intimidad sentimental. Por otro lado, nos dan imágenes de las vivencias de las propias mujeres - de muy distintas procedencias de clase y adscripciones ideológicas acerca de la vida cotidiana, esto es, cómo fue narrada y/o representada y/o vivida la ciudadanía por las mujeres mismas.

Estas narraciones son tomadas aquí como modelos sociales de representación, es decir que, al ubicarse en los borrosos límites entre la ficción y la no ficción - textos que juegan con la ilusión de referencialidad y el principio de veracidad de lo narrado -, permiten analizar una serie de elementos culturales del presente de la escritura. Es decir, la autofiguración de las escritoras en su presente: la imagen que las escritoras tienen de sí mismas y/o la que desean proyectar en función del lector/receptor que ellas mismas construyen en sus textos.

Pero en ningún caso se trata de imágenes aleatorias, sino que forman parte - con diversas acentuaciones y grados de asimilación - de ciertos estereotipos femeninos y masculinos, parámetros obligatorios de normalidad 
construidos históricamente, y cuya violencia simbólica se encuentra en la base de la estructuración patriarcal de las relaciones entre los sexos.

Si el sentido de narrar la propia historia proviene de la intención de dotar de una voz a algo que previamente no lo tiene, ${ }^{7}$ el análisis aquí propuesto acerca de las escrituras de la intimidad de las mujeres antes mencionadas resulta provechoso para explorar las distintas posiciones y las difíciles relaciones construidas por muchas mujeres de principios del siglo XX - excluidas de la esfera pública entre las voces de las mujeres, la identidad y la ciudadanía femenina. Y también, entre sus escrituras - que se abren a lo público - y sus vidas.

A partir de estas consideraciones, a continuación presento un análisis acerca de los relatos de viajes de la escritora y maestra normal Ada María Elflein (1880-1919), reunidos en su libro Por campos históricos (impresiones de viaje) publicado póstumamente, en 1926.

\section{Por campos históricos}

En 1910 se realizaron en Buenos Aires dos congresos de mujeres: el Primer Congreso Feminista Internacional, de tendencia liberal, laica y cosmopolita, y el Congreso Patriótico de Señoras, que representaba a los sectores más tradicionales, católicos y nacionalistas. Ada María Elflein participó en ambos congresos, pues tenía puntos de encuentro y de desencuentro tanto con las feministas como con las nacionalistas. En particular, el punto en el que coincidía con las nacionalistas - y la alejaba de las feministas era precisamente su búsqueda de una definición de la nacionalidad. Pero a la vez promovía nuevos lugares y actividades para las mujeres, para que pudieran 'ampliar sus horizontes' (sic) más allá de los estrechos muros del hogar. En este sentido, impulsaba viajes de mujeres solas (o en grupos de mujeres) es decir, sin que fuese una condición necesaria el hecho de que hubiese hombres en las excursiones, y sostenía que ésta era una vía central de 'educación moral para la mujer'. Además, los lugares a los cuales ella misma iba en estas excursiones con mujeres no respondían a circuitos convencionales sino que se trataba de lugares y recorridos atípicos para la época: lugares del interior del país - buscando allí lo específicamente 'argentino' -, y de difícil acceso (se llegaba a ellos mediante escaladas de montañas, ingreso a minas de carbón, viajes a caballo, entre otras formas), o también de Chile y Uruguay:

Se trata de conocer paisajes que nadie puede divisar desde las ventanillas del tren, ni desde los cojines del automóvil. Se trata de ir allá donde sólo llega la mula 
${ }^{8}$ Ada María ELFLEIN, 1926, p. 23

${ }^{9}$ Quiero agradecer la enorme generosidad de la investigadora Mónica Szurmuck, quien me ha enviado sus trabajos sobre la temática. Szurmuck (2007, p. 144) señala que otra escritora de la misma época, Delfina Bunge de Gálvez, en su libro de viajes Tierras de mar azul, también escapa a esta escritura característica de las narraciones de viajes escritas por mujeres, privilegiando, en cambio, las ideas y las ideologías en un discurso impersonal.

${ }^{10}$ SZURMUCK, 1996, p. 343. con su paso uniforme, calmoso y seguro [...]. Se trata de conocer los paisajes no vulgares de la tierra nativa [...]. Es una manera, y no la menos eficaz, de servir a la patria. La idea puesta en práctica por un centro respetable de educadoras va a alcanzar en esta ocasión, un éxito. ${ }^{8}$

En estas 'escrituras del yo' Elflein expresa un rasgo de cierta autonomía frente a los cánones de la época: hace descripciones de los paisajes, siempre con largas y detalladas referencias históricas, pero se ubica en un lugar de enunciación más bien exterior a la escritura. No se trata de relatos sentimentales sino de descripciones de lugares pintorescos, históricos - en una escritura que se quiere objetiva. Se excluyen todas las referencias personales, que eran características típicas de los relatos de viajes escritos por mujeres. ${ }^{9}$ ¿Por qué esta escritora con pinceladas nacionalistas pero también feministas y que tiene la libertad y la autonomía suficientes como para viajar a lugares atípicos y considerados peligrosos para las mujeres, evita cualquier rasgo de identificación?, ¿cuál es la función de este recurso?, ¿autentificar la ficción, acreditar la realidad de lo histórico?, ¿destilar 'ilusión de verdad' en sus narraciones y así tomar distancia frente a ciertas atribuciones naturalizadas sobre la mujer?, ¿dejar por escrito que las mujeres también pueden 'hacer ciencia'?

Lo que podemos afirmar es que el yo íntimo se oculta en pos de una voz impersonal, social, intelectual, profesional. En este sentido, Elflein se desplaza del estereotipo femenino presente en los escritos de mujeres, que privilegiaban una escritura personal referida a sus sentimientos e intimidad, tanto en la literatura de viajes como en diarios, autobiografías, etc., es decir, en las hoy llamadas 'escrituras del yo'. Este discurso despersonalizado de Elflein se vincula, según Mónica Szurmuck, ${ }^{10}$ con la particular forma de articulación que busca Elflein, de dos corpus teóricos diferentes (nacionalista y feminista). Es decir, propone una idea de lo nacional, de la argentinidad (sic), en la cual hay un espacio para las mujeres que va más allá de la esfera privada. De esta forma, toma distancia de los ideólogos nacionalistas de la época cuya idea del ser nacional tiene sus fundamentos en el discurso de la domesticidad. Este discurso, que encierra a las mujeres en el mundo privado, define su identidad exclusivamente en la maternidad y a la vez las excluye del mundo público, se expresaba no sólo en la literatura y en la prensa, sino que estaba en la base de las leyes vigentes, la medicina, y la educación.

Sin embargo, la acentuación en la educación básica de las mujeres a principios del siglo XX permite ver la doble cara de los procesos sociales, en el sentido de que un mismo 
"Lucía LIONETTI, 2006, p. 853.

${ }^{12}$ ELFLEIN, 1926, p. 88

${ }^{13}$ ELFLEIN, 1926, p. 24

${ }^{14}$ ELFLEIN, 1926, p. 89 proceso puede habilitar prácticas de signo opuesto. Por un lado, la extendida maternalización de las mujeres llevaba a prácticas reproductivas del orden social, al plantear una equivalencia esencial: mujer-madre-maestra. Pero a la vez, este mismo proceso posibilitó caminos liberadores, en el sentido de que comenzó a instalarse la idea de que las mujeres, en tanto formadoras de los futuros ciudadanos, debían acceder, por lo menos, a una educación básica, pasando así del silencio a la palabra. ${ }^{11} Y$ este acceso fue el inicio del largo camino hacia la ciudadanía. Es decir que, en el mismo proceso en el que se afirmaba la ideología maternal, la educación les daba a las mujeres herramientas que les permitirían expandir el universo simbólico, y desde allí, escribir sus propias historias y luchar por sus derechos.

Por otra parte, este discurso impersonal de Elflein quizás podría ser una forma de acomodación a determinados valores hegemónicos - los de la escritura masculina. En este sentido, para tener algún valor, la narración del viaje debería sostenerse en los detallados relatos históricos de cada lugar visitado. El valor estaría dado por este motivo didáctico: aprendemos historia - la historia patriótica oficial, además - al leer sus relatos de viajes: "Yo había venido a Tucumán bajo la fascinación de los recuerdos históricos: quería conocer sobre todo el 'Campo de las Carreras' donde se libró la batalla del año 1812 y la casa donde los representantes de los pueblos declararon en 1816 la independencia argentina". ${ }^{12}$

O también, cuando se refiere a la región de Cuyo: "el teatro de la acción americana del gran capitán José de San Martín". ${ }^{13}$

Ante la vieja pregunta: 'ipor qué los que escriben autobiografías, memorias, etc., creen que su propia historia puede tener algo de interesante para los demás?', Elflein podría responder: 'mis impresiones de viaje sólo tienen valor social si cuento la historia política oficial'. Entonces el recurso al relato histórico, en una línea fundamentalmente nacionalista, funciona como el sostén para narrar sus impresiones de viaje, como una estructura mayor que le da un marco 'válido':

Es necesario difundir el conocimiento de nuestra historia, no para cristalizarnos en la veneración a próceres y descansar a la sombra de los laureles "que supimos conseguir" sino para cosechar en ese campo riquísimo abonado con sangre y amojonado con huesos de héroes y aprender a hacer hoy $y$ en el futuro lo que supieron hacer nuestros mayores. ${ }^{14}$

El relato funciona entonces como responsabilidad histórica, como deber cívico: se recuerda para que no se 
${ }^{15}$ ELFLEIN, 1926, p. 60.

${ }^{16}$ Ricardo FALCÓN, 2000. pierda un pasado común. Y así aprendemos la historia política de nuestro país, de nuestros heroicos antepasados - todos varones - al leer las anotaciones de la escritora y maestra normal, hija de inmigrantes alemanes, que busca la asimilación en aquella sociedad cosmopolita y nacionalista a la vez.

Entonces, por un lado, Elflein desafía las convenciones patriarcales y viaja sola (o con alguna/s compañera/ $s$ de viaje) hacia aventuras arriesgadas. No pide permiso para emprender estas aventuras que no eran comunes entre las mujeres.

Por otro lado, no deja de decirnos que la función de estos viajes por el interior del país es 'una forma de educación física y moral' para la mujer:

la mujer extiende sus propios horizontes, adquiere conocimientos geográficos valiosos, comprende y se vincula más al alma nacional y desarrolla energías que son fuerzas vitales, latentes en todas las mujeres condenadas por ambientes de ficción o por necesidades profesionales, a vivir ovilladas durante meses o años, en las ciudades, en aulas o en oficinas. ${ }^{15}$

Pero estas elaboraciones críticas del lugar doméstico asignado a las mujeres en la época conviven con una visión acrítica de la historia argentina, que retoma la narración nacionalista hegemónica que se gestaba en los tiempos del Centenario. Cabe señalar que en estos años aparecen las primeras críticas estratégicas al proyecto modernizador impulsado por la generación del 80', en las voces del llamado nacionalismo telúrico cuyas principales figuras son Manuel Galvez, Ricardo Rojas y Leopoldo Lugones. Según Ricardo Falcón, ${ }^{16}$ estas tendencias tradicionalistas expresaban el resentimiento de las oligarquías provinciales que el proyecto agroexportador había excluido o incluido en forma marginal.

$Y$ aquel patriotismo nacionalista se afirmaba en la exclusión de lo diferente, revalorizando al 'gaucho' del interior frente al nuevo bárbaro: el extranjero. Un ejemplo paradigmático se puede ver en las conferencias de Leopoldo Lugones de 1913, publicadas luego bajo el título El payador, donde hay una exaltación de la figura del gaucho como emblema de la identidad nacional.

\section{Conclusiones}

La forma que tiene Elflein de validar sus impresiones de viaje es convencional: está sujeta con firmeza a las restricciones de la historia, saturada de fechas, lugares $y$ nombres, en una sucesión ordenada y lineal de hechos y explicaciones. En este sentido, hoy podemos encontrar, efectivamente, un valor histórico en los relatos de Elflein, pero 
${ }^{17}$ Susan KIRKPATRICK, 1991, p. 20

${ }^{18}$ Con un fuerte apoyo de las feministas socialistas, en mayo de 1918 el senador socialista Enrique Del Valle Iberlucea presentó en el Congreso de la Nación su proyecto de emancipación civil de la mujer, que luego sirvió de base a la futura Ley nro. 11.357, aprobada en 1926. Esta "Ley de ampliación de la capacidad civil de la mujer" ampliaba, como su nombre lo indica, los derechos civiles de las mujeres solteras, divorciadas o viudas, reconociendo la igualdad de derechos civiles con los hombres. Si bien esta ley eliminaba restricciones de Código Civil para las mujeres casadas, aún no se les reconocía la plena igualdad civil, puesto que no las habilitaba para disponer a título gratuito de bienes propios, ni a ejercer la patria potestad de sus hijos menores - que le correspondía al marido - ni a aceptar herencias sin beneficio de inventario, ni a dejar de habitar con el marido sino en caso de riesgo para su vida, ni a donar bienes o repudiar herencia sin autorización del marido, entre otros derechos. este valor no estaría dado por el hecho de que nos enseñan 'la historia de la patria y de los padres fundadores' como parecía buscar Elflein, sino más bien porque documentan formas de autorrepresentación de mujeres que contaban con las herramientas educativas del normalismo, y que por lo tanto tenían mayores posibilidades para deslizarse, al menos parcialmente, de los estereotipos femeninos de la época.

Quizás, esta ambivalencia entre autonomía y acomodación que se puede notar en el discurso impersonal de Elflein fuera una forma posible de acceder a espacios públicos vedados para las mujeres: tanto el reconocimiento de la pluma femenina, como el acceso a lugares geográficos atípicos. Pero también se puede vincular con las contradicciones que atravesaban a las mujeres en la elaboración romántica de un lenguaje de subjetividad desde el siglo XVIII: ${ }^{17}$ por un lado, habría una mayor participación de las mujeres mediante la revalorización del sentimiento y de la individualidad - lo cual podría impulsar a las mujeres ilustradas a la escritura, al menos en los géneros aceptados socialmente para ellas. Pero a la vez, las mujeres habían sido definidas según su "naturaleza" maternal, sensible y tierna, produciendo un ideal femenino que se fundaba en la falta de deseo - que, en cambio, había quedado exclusivamente vinculado a la identidad masculina. Entonces, ¿cómo conciliar esta posibilidad de vida - de escritura -, que aparecía a través de la revalorización del sentimiento y la individualidad, con el ideal de mujer basado en la ausencia de deseo?

En síntesis, podría ser entonces una forma de pensar las diversas luchas por la inclusión de las mujeres en una sociedad que las excluía de los derechos civiles y políticos. Sin embargo, esta ambivalencia de Elflein podría expresar que su búsqueda no se inclinaba tanto hacia el reconocimiento de las mujeres como ciudadanas - con iguales derechos que los varones -, sino que se ceñía a un objetivo más modesto: la reivindicación de mayor independencia intelectual y moral para las mujeres. De modo que quizás esta posición de la escritora normalista puede interpretarse como una forma particular de apropiarse de algunos derechos - exclusivamente reservados a los varones hasta $1926^{18}$ - en los intersticios de la sociedad patriarcal de principios del siglo XX.

\section{Referencias}

BARRANCOS, Dora. Mujeres en la sociedad argentina: una historia de cinco siglos. Buenos Aires: Sudamericana, 2007. 
BECERRA, Marina. Marxismo y feminismo en el primer socialismo argentino: Enrique Del Valle Iberlucea. Rosario, Argentina: Prohistoria Ediciones, 2009.

CATELLI, Nora. "El espacio autobiográfico". In: __ . En la era de la intimidad. Rosario: Beatriz Viterbo, 2007. p. 213411.

DEL VALLE IBERLUCEA, Enrique. "El divorcio: sus fundamentos científicos". In: El divorcio y la emancipación civil de la mujer. Buenos Aires: Empresa Cultura y Civismo, 1919. p. 153-207.

ELFLEIN, Ada María. Por campos históricos (impresiones de viaje). Buenos Aires: Talleres Gráficos Argentinos L. J. Rosso, 1926.

FALCÓN, Ricardo. "Militantes, intelectuales e ideas políticas". In:__ (Comp.). Nueva historia argentina: democracia, conflicto social y renovación de ideas (1916-1930). Buenos Aires: Editorial Sudamericana, 2000.

HEILBRUN, Carolyn. "No-autobiografías de mujeres 'privilegiadas': Inglaterra y América del Norte". In:__. La autobiografía y sus problemas teóricos. Barcelona: Anthropos, 1991. p. 106112.

KIRKPATRICK, Susan. Las románticas: escritoras y subjetividad en España, 1835-1850. Madrid: Cátedra, 1991.

LIONETTI, Lucía. "La educación de las mujeres en América Latina: formadoras de ciudadanos". In: MORANT, Isabel (Dir.). Historia de las mujeres en España y América Latina. III. Del siglo XIX a los umbrales del XX. Madrid: Cátedra, 2006. p. 849-869.

LOUREIRO, Angel. "Problemas teóricos de la autobiografía". In: . La autobiografía y sus problemas teóricos. Barcelona: Anthropos, 1991. p. 2-8.

MOLLOY, Sylvia. Acto de presencia: la escritura autobiográfica en Hispanoamérica. México: Fondo de Cultura Económica, 1996.

PATEMAN, Carole. El contrato sexual. España: Anthropos, 1995. SMITH, Sidonie. "Hacia una poética de la autobiografía de mujeres". In: . La autobiografía y sus problemas teóricos. Barcelona: Anthropos, 1991. p. 93-105.

SZURMUK, Mónica. "Ada María Elflein: viaje al interior de las identidades". Monographic Review, EE UU, Texas Tech University, v. XII, 1996.

. Miradas cruzadas: narrativas de viaje de mujeres en Argentina 1850-1930. México: Instituto Mora, 2007.

[Recebido em 27 de fevereiro de 2011 reapresentado em 11 de abril de 2011 e aceito para publicação em 10 de maio de 2011] 
'What do Women want?' Women's Citizenship and Private Writing in Argentina's Early 20th Century

Abstract: The so-called "private writings" - autobiographies, letters, travel journals, diaries allow us to analyze the possible interstices between the private and the public sphere in a historical moment in which legal rights were clearly pre-defined according to gender. In this sense, "private writings" permit us to reflect upon women's strategies to speak their own minds in the public arena, in a context in which they were confined to the domestic sphere. My starting point is the insoluble conflict put forward by one of the first male voices to stand for women's rights in Argentina - the Socialist Enrique Del Valle Iberlucea - in order to analyze the ways in which women's citizenship is narrated - lived? Represented? - by women themselves. For that, I examine both the reports of female-writer's travel journals and those of a schoolteacher: Ada María Elflein (1880-1919).

Key Words: Feminine Citizenship; Private Writings; Socialism; Travel Journals.

880 Estudos Feministas, Florianópolis, 20(3): 869-880, setembro-dezembro/2012 